\title{
Análise da temperatura de superfície de vilas e aglomerados de Belo Horizonte através de série temporal de imagens de sensoriamento remoto
}

\author{
Fabrício Lisboa Vieira Machado ${ }^{1}$
}

\begin{abstract}
Resumo: Diante da baixa cobertura por estações meteorológicas oficiais para avaliar fenômenos climáticos urbanos, o sensoriamento remoto se destaca como interessante recurso, podendo ser empregado para a detecção de núcleos de calor. Dessa forma, a pesquisa objetivou estudar a distribuição temporal e espacial da temperatura de superfície no município de Belo Horizonte, identificando a possível relação de núcleos de calor com a localização de vilas e aglomerados, que ocupam $5 \%$ do território. Foram utilizadas imagens do satélite Landsat-8 entre os anos de 2013 e 2020, a partir das quais se calculou a temperatura superficial para conjunto de 29 datas distintas. Os resultados indicaram que não necessariamente as vilas e aglomerados figuram como núcleos térmicos significativos, tendo sido mais associados a galpões e estruturas com extenso revestimento metálico, que se mostraram até $8,7^{\circ} \mathrm{C}$ mais quentes, em média, do que as superfícies de entorno. A pesquisa, porém, não foi suficiente para responder se, do ponto de vista da temperatura do ar, os espaços investigados apresentam comportamento distinto quando comparados aos bairros com padrão ordenado de arruamento e edificações.
\end{abstract}

Palavras-chave: Temperatura de superfície; Vilas e aglomerados; Núcleos de calor urbano; Sensoriamento Remoto.

\section{Land surface temperature analysis of settlements in Belo Horizonte through time series of remote sensing images}

Abstract: In view of the low coverage by official meteorological stations to assess urban climatic phenomena, remote sensing stands out as an interesting resource, which can be used for the detection of heat cores. Thus, the research aimed to study the temporal and spatial distribution of surface temperature in the city of Belo Horizonte, identifying the possible relationship of heat cores with the location of villages and settlements, which occupy $5 \%$ of the territory. Images from the Landsat- 8 satellite were used between the years 2013 and 2020, from which the surface temperature was calculated for a set of 29 different dates. The results indicated that not necessarily the villages and settlements appear as significant thermal cores, having been more associated with warehouses and structures with extensive metallic coating, which were up to $8.7^{\circ} \mathrm{C}$ warmer, on average, than the surrounding surfaces. The survey, however, was not enough to answer whether, from the point of view of air temperature, the spaces investigated show different behavior when compared to neighborhoods with an orderly pattern of streets and buildings.

Keywords: Land surface temperature; Villages and settlements; Urban heat cores; Remote Sensing.

\footnotetext{
${ }^{1}$ Universidade Federal de Minas Gerais | fabriciolvm@ufmg.br.
} 


\section{1 - INTRODUÇÃO E OBJETIVOS}

O número insuficiente de estações meteorológicas oficiais é desafio comum à pesquisa climatológica brasileira. À exceção de grandes centros urbanos, em que são observadas até quatro ou cinco estações do Instituto Nacional de Meteorologia (Inmet), como nos casos de Belo Horizonte e Rio de Janeiro, a grande maioria dos municípios sequer possui rede automática ou convencional para monitoramento dos elementos do clima (INMET, 2021).

A disposição da rede meteorológica oficial, quando disponível, também tende a refletir condições climáticas muito mais voltadas às escalas regionais e/ou sub-regionais, conforme definidas por Monteiro (1976; 2003), do que aos aspectos do clima produzidos pela especificidade dos tecidos urbanos. Mas é justamente em ambientes intraurbanos e nas escalas inferiores do clima, que as alterações no balanço de energia provocadas pela produção antrópica do espaço são mais sensíveis e significativas, como discutido por Ribeiro (1993), Sant'anna Neto (1998), Azevedo (2001) e Fialho (2009).

Com a malha amostral precária, torna-se tarefa árdua desenvolver pesquisa em espaços urbanos carentes de ordenamento territorial e de equipamentos públicos voltados à minimização de impactos negativos à população, como em vilas e aglomerados de baixa renda. Resultado disso é que permanece pouco estudado o comportamento do clima neste ambientes, cujo padrão de ocupação e de construção das habitações pode desencadear condições microclimáticas muito específicas, como o aprisionamento de calor pela proximidade de estruturas construídas, a obstrução da abóbada celeste pelo adensamento de pavimentos e o sombreamento perene de becos e ruelas dispostos de maneira não favorável à iluminação, como destacam Silva \& Ribeiro (2005; 2006) e Machado \& Jardim (2014) em trabalhos preliminares realizados, respectivamente, em Paraisópolis - São Paulo, e no Aglomerado da Serra - Belo Horizonte.

A capital mineira, por exemplo, totaliza 218 vilas e aglomerados de baixa renda, com população de mais de 372 mil habitantes, distribuída em área total de 15,6 km² ou 5\% do território, conforme dados georreferenciados da Empresa de Informática e Informação do Município de Belo Horizonte (PRODABEL, 2020), representados no mapa 1 a seguir. Ainda assim, nenhuma das estações meteorológicas oficiais da capital se localiza a menos de 500 metros de distância de vila ou aglomerado, o que ressalta a dificuldade de conduzir pesquisa climatológica nestes espaços a partir de insumos convencionais. 
Diante da dificuldade exposta, o emprego do sensoriamento remoto pode se destacar como interessante técnica de análise de fenômenos climáticos, em especial da temperatura de superfície terrestre, ao possibilitar, através de séries temporais de imagens termais, a investigação de fenômenos climáticos em grandes extensões de maneira contínua, como observado nos trabalhos brasileiros de Lombardo (2003), Coelho \& Correa (2013), Maciel \& Oliveira (2016), Bezerra et al. (2018), Sousa \& Lima (2021), entre outros.

Mapa 1: Localização das vilas, aglomerados e estações meteorológicas oficiais de Belo Horizonte (MG).

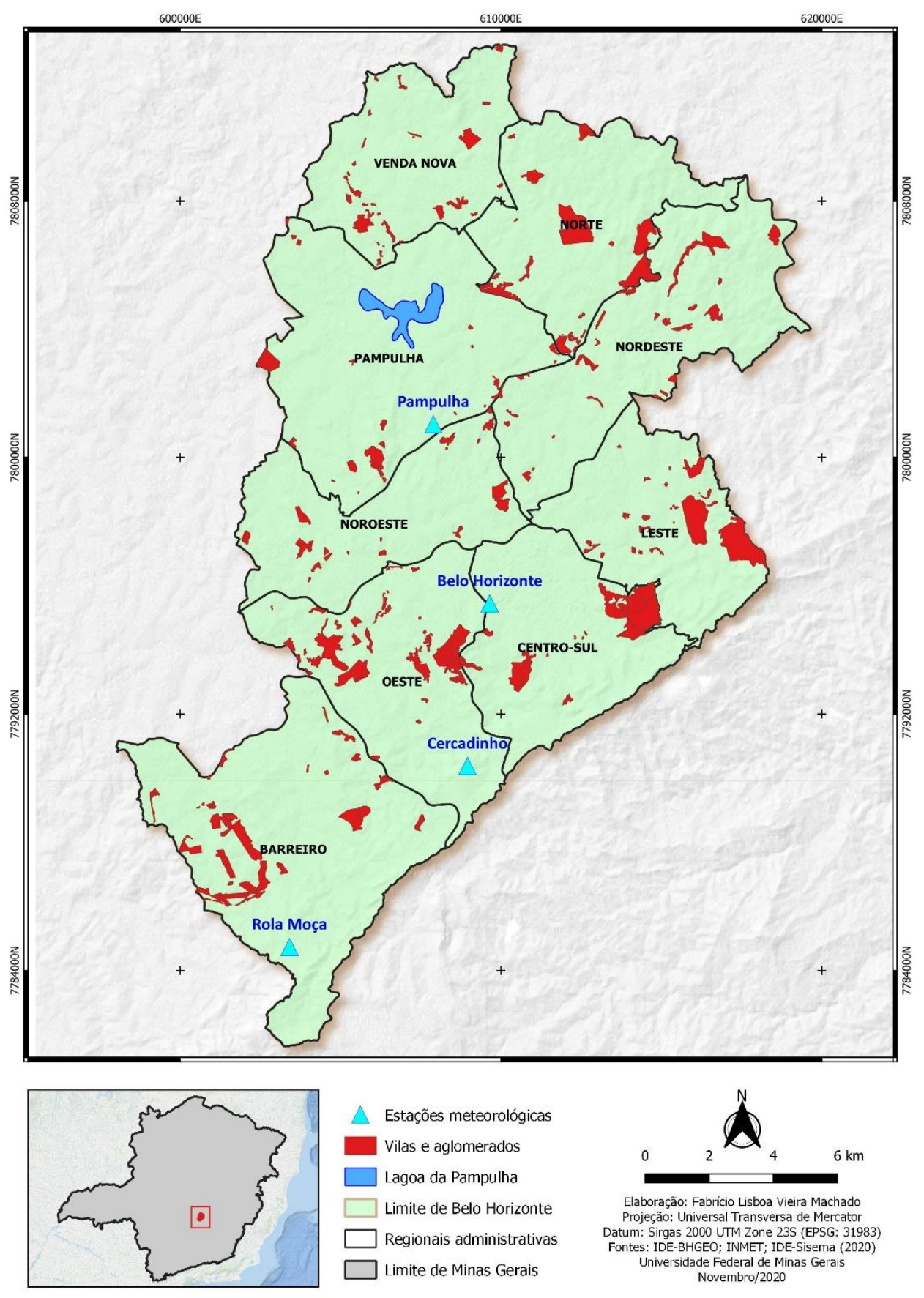


Desde 2013, o satélite Landsat-8, por exemplo, oferece imagens de banda termal de maneira gratuita, através de repositórios oficiais disponíveis em ambiente web. Com a modelagem deste insumo, cartas referentes à temperatura da superfície podem ser produzidas para toda a extensão de Belo Horizonte, retratando a condição térmica dos materiais que revestem o tecido do município em variados anos, tipos de tempo e estações sazonais, conforme realizado por Barbosa et al. (2017) em exemplo na aglomeração urbana de Rennes - França.

A despeito das limitações intrínsecas ao uso de produtos orbitais para estudos climáticos $^{2}$, sobretudo na escala em que as vilas estão organizadas, destaca-se o papel relevante do sensoriamento remoto na avaliação da temperatura de superfície a partir de série temporal contínua, contribuindo para a identificação de núcleos de calor urbanos recorrentes no tempo e no espaço e para investigação de sua relação com os aglomerados de baixa renda de Belo Horizonte.

Dessa forma, o presente artigo objetiva avaliar a distribuição temporal e espacial da temperatura de superfície de Belo Horizonte, identificando a possível relação de núcleos de calor urbanos com a localização de vilas e aglomerados.

\section{2 - METODOLOGIA}

Para alcance dos objetivos propostos, foram adquiridas, através da plataforma Earth Explorer do United States Geological Survey (USGS), todas as cenas brutas ${ }^{3}$ da banda B10 do sensor infravermelho termal (TIRS) do satélite Landsat-8, entre os anos de 2013 e 2020, com índice de cobertura de nuvem inferior a 10\% para a área de estudo.

O satélite foi escolhido em virtude das características específicas dos sensores embarcados, sobretudo dos canais termais de operação, que são comparativamente superiores a outros satélites disponíveis em repositórios abertos. No total, foram utilizadas 29 imagens de datas e períodos distintos, em condições aderentes à pesquisa. O quadro 1 resume a especificação técnica dos produtos gerados pelo Landsat- 8 .

Quadro 01: Características das bandas espectrais dos sensores OLI e TIRS do satélite Landsat 8. Adaptado de United States Geological Survey (USGS).

\footnotetext{
${ }^{2}$ Como a baixa resolução espacial das bandas termais de satélites disponíveis gratuitamente ou a elevada cobertura por nebulosidade durante tipos de tempo instáveis.

3 Nível de processamento de dados \#1, da coleção \#1: rasters fornecidos com pré-tratamento para correção radiométrica e posicional.
} 
Quadro 1: Características das bandas espectrais dos sensores OLI e TIRS do satélite Landsat 8. Adaptado de United States Geological Survey (USGS).

\begin{tabular}{|c|c|c|c|c|c|c|}
\hline Sensor & Bandas espectrais & $\begin{array}{c}\text { Resolução } \\
\text { espacial (m) }\end{array}$ & \begin{tabular}{|c|}
$\begin{array}{c}\text { Resolução } \\
\text { espectral }(\mu \mathrm{m})\end{array}$ \\
\end{tabular} & \begin{tabular}{|c|} 
Resolução \\
radiométrica
\end{tabular} & $\begin{array}{l}\text { Resolução } \\
\text { temporal }\end{array}$ & $\begin{array}{c}\text { Faixa } \\
\text { imageada }\end{array}$ \\
\hline \multirow{9}{*}{$\begin{array}{c}\text { Operational } \\
\text { Land Imager - OLI }\end{array}$} & B1 (Costeiro/Aerossol) & 30 & $0,43-0,45$ & \multirow{11}{*}{16 bits } & \multirow{11}{*}{16 dias } & \multirow{11}{*}{$\begin{array}{c}185 \times 180 \\
\mathrm{~km}\end{array}$} \\
\hline & B2 (Azul) & 30 & $0,45-0,51$ & & & \\
\hline & B3 (Verde) & 30 & $0,53-0,59$ & & & \\
\hline & B4 (Vermelho) & 30 & $0,64-0,67$ & & & \\
\hline & B5 (Infravermelho próximo) & 30 & $0,85-0,88$ & & & \\
\hline & B6 (Infravermel ho de ondas curtas) & 30 & $1,57-1,65$ & & & \\
\hline & B7 (Infravermel ho de ondas curtas) & 30 & $2,11-2,29$ & & & \\
\hline & B8 (Pancromática) & 15 & $0,50-0,68$ & & & \\
\hline & B9 (Cirros) & 30 & $1,36-1,38$ & & & \\
\hline \multirow{2}{*}{$\begin{array}{c}\text { Thermal infrared } \\
\text { sensor - TIRS }\end{array}$} & B10 (Infravermel ho termal) & 100 & $10,6-11,19$ & & & \\
\hline & B11 (Infravermel ho termal) & 100 & $11,5-12,51$ & & & \\
\hline
\end{tabular}

Conforme postulado por Planck e Boltzman na transição entre os séculos XIX e XX, todo corpo com temperatura acima de $-273^{\circ} \mathrm{C}$ emite radiação em determinada faixa do espectro eletromagnético, sendo ela função exclusiva da sua temperatura e emissividade (NOVO, 2010). É preferencialmente na faixa do infravermelho termal (entre 3 e $20 \mu \mathrm{m}$ ) que a perda de radiação da superfície terrestre para a atmosfera por ondas longas ocorre e, dessa maneira, o sensor TIRS embarcado no satélite Landsat-8 é capaz de converter a radiação captada em sinal passível de leitura. Esse sinal é transformado em números digitais (DN) de um produto rasterizado (pixels de uma imagem), que pode ser finalmente convertido em temperatura através de álgebras em softwares específicos de processamento de imagens de sensoriamento remoto ou Sistemas de Informação Geográfica (GIS).

De posse da série temporal de imagens Landsat- 8 citada foi realizada etapa de cálculo dos parâmetros de conversão em ambiente GIS, de modo a realizar o processamento inicial das imagens adquiridas e elaborar as cartas de temperatura de superfície para Belo Horizonte nos diversos períodos. Todos os processos foram integralmente realizados através do software livre e de código-aberto QGIS 3.16.4.

Em ambiente GIS, todas as imagens foram inicialmente reprojetadas ao sistema de referência de coordenadas Sirgas 2000, adotado pelo Instituto Brasileiro de Geografia e Estatística (IBGE) como datum oficial do sistema geodésico brasileiro e cartográfico nacional ${ }^{4}$. Também foi adotada projeção Universal Transversa de Mercator (UTM), em fuso 23S (área de estudo), de modo a possibilitar recorte da máscara do município de Belo Horizonte e cálculo mais assertivo de medidas geométricas, quando necessárias.

\footnotetext{
${ }^{4}$ Resolução IBGE nº 01/2015.
} 
Em seguida, empregou-se a calculadora raster do software para converter os números digitais (DN) da banda B10 para radiância no topo da atmosfera, através de equação (1) do USGS, baseada em Artis \& Canahan (1982):

$$
L \lambda=M_{L} Q_{c a l}+A_{L}
$$

Onde:

$\mathrm{L} \lambda=$ valor da radiância espectral no topo da atmosfera (TOA), medida em Watts $/ \mathrm{m}^{2} *$ srad $* \mu \mathrm{m}$;

$\mathrm{ML}=$ fator multiplicativo escalonado específico constante no arquivo de metadado que acompanha as imagens do satélite;

Qcal = produto padrão quantificado e calibrado por valores de pixel (DN);

$\mathrm{AL}=$ fator aditivo escalonado específico constante no mesmo arquivo de metadado.

Uma vez calculada, a radiância espectral foi convertida para temperatura de brilho, expressa em graus Kelvin, a partir de equação (2) fornecida pelos mesmos autores. Para realizar a conversão para graus Celsius, foi aplicada adicionalmente a equação (3), apresentada a seguir.

$$
T_{K}=K_{2} / \ln \left(\frac{k_{1}}{L_{\lambda}}+1\right)
$$

Onde:

$\mathrm{Tk}=$ temperatura de brilho aparente em graus Kelvin $(\mathrm{K})$;

$\mathrm{L} \lambda=$ reflectância no topo da atmosfera (Watts $\left./\left(\mathrm{m}^{2} * \operatorname{srad}^{*} \mu \mathrm{m}\right)\right)$;

$\mathrm{k} 1$ = constante de conversão K1 específica para cada banda, também denominada de constante térmica, disponível no arquivo de metadado;

$\mathrm{K} 2$ = constante de conversão K2 específica para cada banda, também denominada de constante térmica, disponível no arquivo de metadado.

$$
T_{C}=T_{K}-273
$$

Onde:

$\mathrm{Tc}=$ temperatura de superfície em graus Celsius $\left({ }^{\circ} \mathrm{C}\right)$.

É importante destacar que diversos estudos como os de Bastiaanssen (1995), Sobrino et al. (2001), Jiménez-Muñoz et al. (2003; 2009) e Grondona \& Rolim (2016) realizaram esforços para estimar a temperatura de superfície terrestre a partir de modelos de correção atmosférica e de calibração em função da emissividade dos alvos. Contudo, o presente 
trabalho optou pela adoção do modelo simplificado de cálculo da temperatura de superfície, acima apresentado, em razão do montante de cenas utilizadas e dos propósitos iniciais da pesquisa.

Para possibilitar a realização em lote da etapa de álgebra de mapas para as 29 cenas utilizadas na pesquisa, foi desenvolvido roteiro de cálculo através de ferramenta de modelagem gráfica do QGIS. Os principais processos envolvidos podem ser visualizados na figura 1 a seguir.

Figura 1. Fluxograma-síntese para implementação das etapas de cálculo da temperatura de superfície terrestre em ambiente GIS.

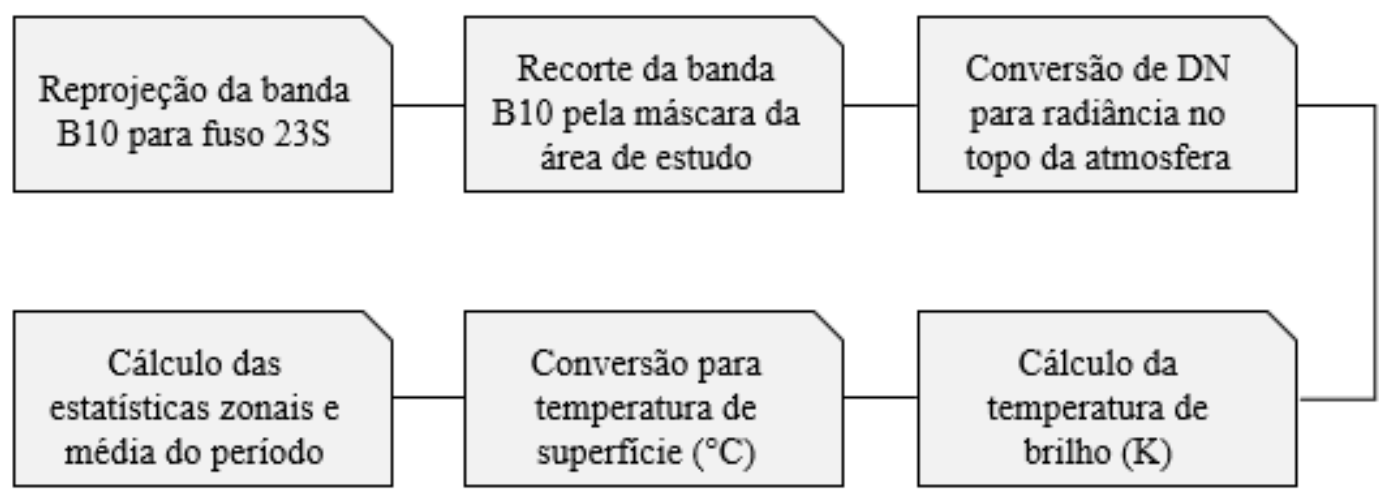

Em seguida, com a utilização da ferramenta de estatística zonal, foram calculadas as temperaturas médias, mínimas e máximas de Belo Horizonte e do conjunto de vilas e aglomerados em todas as cartas geradas na etapa anterior. Os dados foram tabulados através do Microsoft Excel para apresentação em tabelas e gráficos.

Ainda, de modo a avaliar a correlação estatística existente entre os dados de temperatura de superfície gerados a partir das imagens Landsat- 8 com dados de temperatura do ar medidos por estações meteorológicas do Inmet, adquiriu-se a série histórica de dados da Estação Pampulha, localizada no interior do campus da Universidade Federal de Minas Gerais (UFMG). Da série, extraiu-se os valores de temperatura do ar medidos nos mesmos dias e horários de passagem do satélite nas imagens trabalhadas (13:00h UTC) e através do QGIS, foram identificados os valores de temperatura calculados para o pixel da imagem correspondente à localização da estação meteorológica in situ.

Diferentemente do realizado por Pinto et al. (2017), que avaliou a correlação das variáveis "temperatura de superfície" e "temperatura do ar" de Belo Horizonte a partir de observação pontual (único dia) e interpolação de dados, optou-se aqui pelo cálculo da 
regressão linear para o conjunto de 29 observações avaliadas ${ }^{5}$, de modo a identificar se a eventual correlação existente se manteve durante o período de estudo. Por outro lado, o presente artigo se limitou a correlacionar dados de apenas uma estação meteorológica, visto que as Estações Cercadinho e Rola Moça se localizam em contextos peri-urbanos não interessantes aos propósitos da pesquisa. A Estação $5^{\circ}$ DISME, por outro lado, não foi utilizada por se tratar de tipo convencional e não registrar dados no horário de passagem do satélite Landsat- 8 .

Para os resíduos da regressão, em especial os mais significativos, avaliou-se as cartas sinóticas e imagens de satélites meteorológicos das datas em que ocorreram, de modo a compreender as condições atmosféricas em que a temperatura da superfície não foi suficiente para explicar estatisticamente o comportamento da temperatura do ar (tendo em vista que o ar aquece por irradiação de calor superficial).

Por fim, foi calculada a distribuição média da temperatura de superfície para o período em análise, a partir da qual foram retomados os fatores geográficos e processos físicos responsáveis pelos cenários observados, além de avaliada a ocorrência espacial dos principais núcleos de calor em relação à localização geográfica das vilas e aglomerados de Belo Horizonte.

\section{3 - RESULTADOS}

Entre 25/08/2013 e 29/09/2020 (datas respectivas das imagens mais antigas e mais recentes utilizadas na pesquisa), a maior temperatura de superfície calculada em Belo Horizonte foi de $43,7^{\circ} \mathrm{C}$, justamente na última data citada, período marcado por episódios sucessivos de ondas de calor e de repercussão dos impactos negativos às populações pela mídia ${ }^{6}$. Contudo, não raros foram os registros de temperatura superficial acima de $40^{\circ} \mathrm{C}$ na capital mineira durante o período de análise, tendo ocorrido oito vezes no total, o que representa aproximadamente $28 \%$ das observações.

O que se destaca a partir disso, porém, é que a localização dos picos de temperatura superficial não necessariamente esteve relacionada às áreas de elevado adensamento populacional e de massa edificada (como as vilas e aglomerados). $\mathrm{Na}$ verdade, na quase totalidade dos casos, os maiores núcleos de aquecimento superficial estiveram associados aos

\footnotetext{
${ }^{5}$ Foi utilizado o pacote estatístico GeoDa.

${ }^{6}$ A exemplo, matéria do Jornal Estado de Minas intitulada “ $\mathrm{Com} 37,3^{\circ} \mathrm{C}$, $\mathrm{BH}$ tem setembro mais quente da história; confira recordes", disponível em https://www.em.com.br/app/noticia/gerais/2020/09/28/interna_gerais,1189674/com-37-3-c-bh-temsetembro-mais-quente-da-historia-confira-recordes.shtml.
} 
telhados de grandes estruturas, como galpões de logística e distribuição, centros de exposição, shoppings, entre outros. Isso está relacionado à propriedade física de materiais que comumente são utilizados para revestir tais estruturas, como o zinco e o metalon. Nestes dois casos, o calor específico dos materiais é baixíssimo (aproximadamente $0,093 \mathrm{cal} / \mathrm{g}^{\circ} \mathrm{C}$ ), o que faz com que o aquecimento em função da radiação solar direta incidida seja muito veloz. Além disso, a espessura dos telhados com esse tipo de material geralmente é muito fina, o que contribui para a propagação do calor para toda a extensão do revestimento.

De tal maneira, mesmo em áreas de Belo Horizonte com elevada densidade de edificações no entorno, a presença de grandes estruturas com telhados metálicos atraiu o pico de temperatura superficial calculada. Cenário interessante de se destacar, neste caso, é o que ocorre em um dos maiores centros de exposição da América Latina, localizado na capital mineira. O intitulado "Expominas" apresenta dimensões significativas e é revestido por extensa estrutura metálica. Dessa forma, mesmo com a presença de uma das mais expressivas e populosas vilas de Belo Horizonte nas imediações (a “Cabana do Pai Tomás”), os núcleos de aquecimento observados em condições de tempo estável (quente) e pós-frontal (frio) estiveram todos vinculados ao Expominas, conforme pode ser verificado na figura 2 para os dias 25/06/2014 e 29/09/2020 a seguir.

Figura 2: Temperatura de superfície $\left({ }^{\circ} \mathrm{C}\right)$ nas vilas e aglomerados de entorno do centro de exposição Expominas (destaque), nos dias 25/06/2014 (esquerda) e 29/09/2020 (direita).
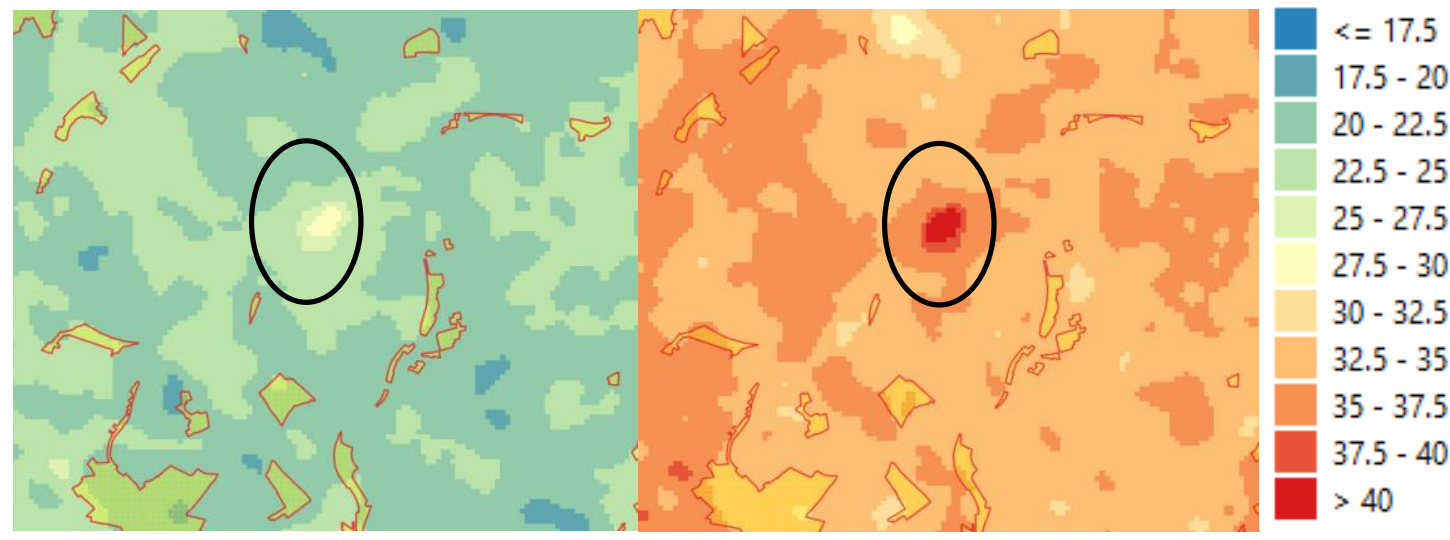

Cabe ressaltar que o dia 25/06/2014 foi, inclusive, detentor da menor temperatura de superfície calculada no período de análise $\left(14,1^{\circ} \mathrm{C}\right)$ e, também, da menor temperatura média $\left(21,3^{\circ} \mathrm{C}\right)$ dentre as 29 observações. A despeito da situação pós-frontal observada, não foi registrada precipitação pelas estações meteorológicas de Belo Horizonte neste dia, o que poderia auxiliar na interpretação dos cenários observados. Tratou-se, portanto, de significativo controle atmosférico por sistema subpolar. 
Outra situação interessante a destacar é o papel da vegetação na regulação da temperatura de superfície. Mesmo nas vilas e aglomerados de maior extensão territorial e adensamento de edificações, as áreas com manutenção de formações vegetacionais, como fundos de vale, encostas e cabeceiras, se mostraram sensíveis ao sensor, mesmo com a limitação da resolução espacial da banda termal (100 metros). Isso ocorre majoritariamente nas vilas que compõem o Aglomerado da Serra e no Conjunto Taquaril, onde os fundos de vale vegetados acompanharam a distribuição espacial das temperaturas mínimas.

Tais comportamentos são explicados em virtude da manutenção de umidade no solo pelas espécies vegetais e pelo processo de evapotranspiração das plantas, que cria contextos micro e topoclimáticos específicos. Além disso, ambas as localidades estão inseridas em unidade climática distinta da grande maioria das vilas de Belo Horizonte, associada aos climas locais do conjunto de serras do Quadrilátero Ferrífero, conforme delimitados por Assis (2010). A figura 3 revela o cenário discutido.

Figura 3: Distribuição da temperatura de superfície $\left({ }^{\circ} \mathrm{C}\right)$ nas áreas vegetadas do Aglomerado da Serra (sudoeste) e Conjunto Taquaril (nordeste) no dia 01/06/2017.
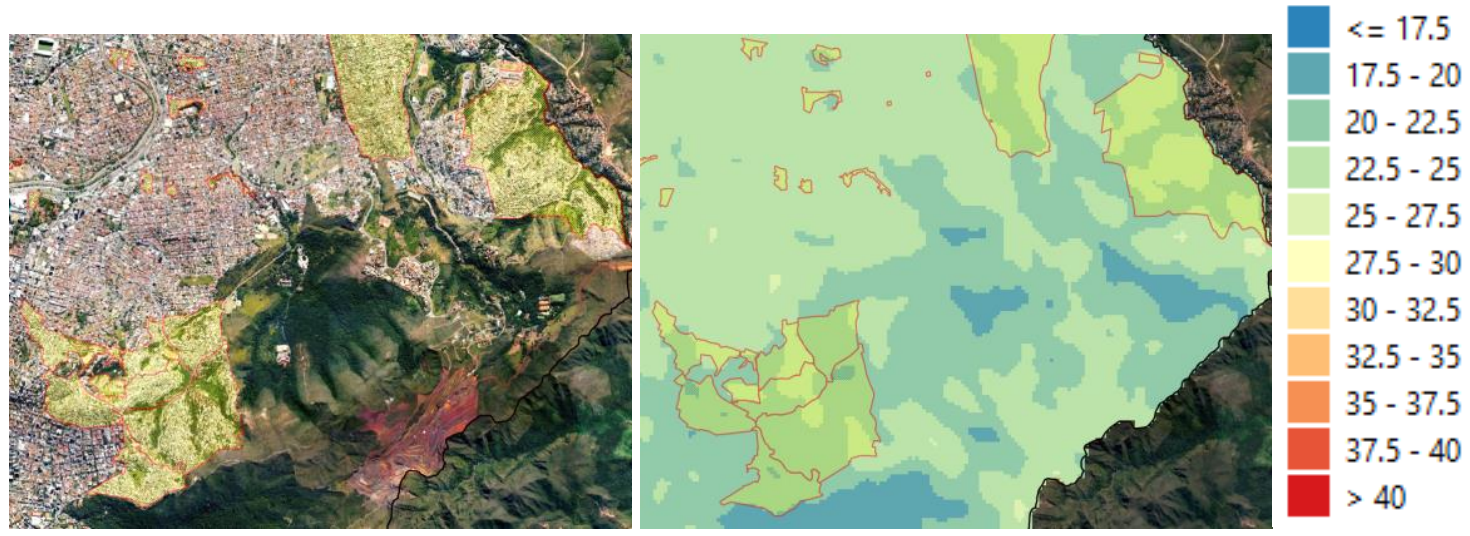

É interessante destacar, ainda, as condições de temperatura superficial observadas no entorno das vilas "Pedreira Prado Lopes", "Buraco Quente" e "Concórdia”, na divisa entre as regionais Noroeste e Nordeste de Belo Horizonte, e na Vila Apolônia, na regional Venda Nova. Apesar de densamente edificadas, as vilas citadas dividem espaço com bairros populares que, apesar de possuírem padrão ordenado de arruamento e cobertura por telha cerâmica colonial na maioria das moradias, também se mostram fortemente ocupados. Essa condição foi sensível à média-baixa resolução do sensor, que os considerou em faixa de temperatura superficial muito semelhante, como observado nos exemplos datados de 03/01/2015 (verão) e 02/10/2015 (primavera), com temperaturas oscilando entre $33^{\circ} \mathrm{C}$ e $30^{\circ} \mathrm{C}$, respectivamente (figura 4 ). 
Figura 4: Temperatura de superfície $\left({ }^{\circ} \mathrm{C}\right)$ calculada para as vilas "Pedreira Prado Lopes", "Buraco Quente" e "Concórdia" em 03/01/2015 e 02/10/2015.
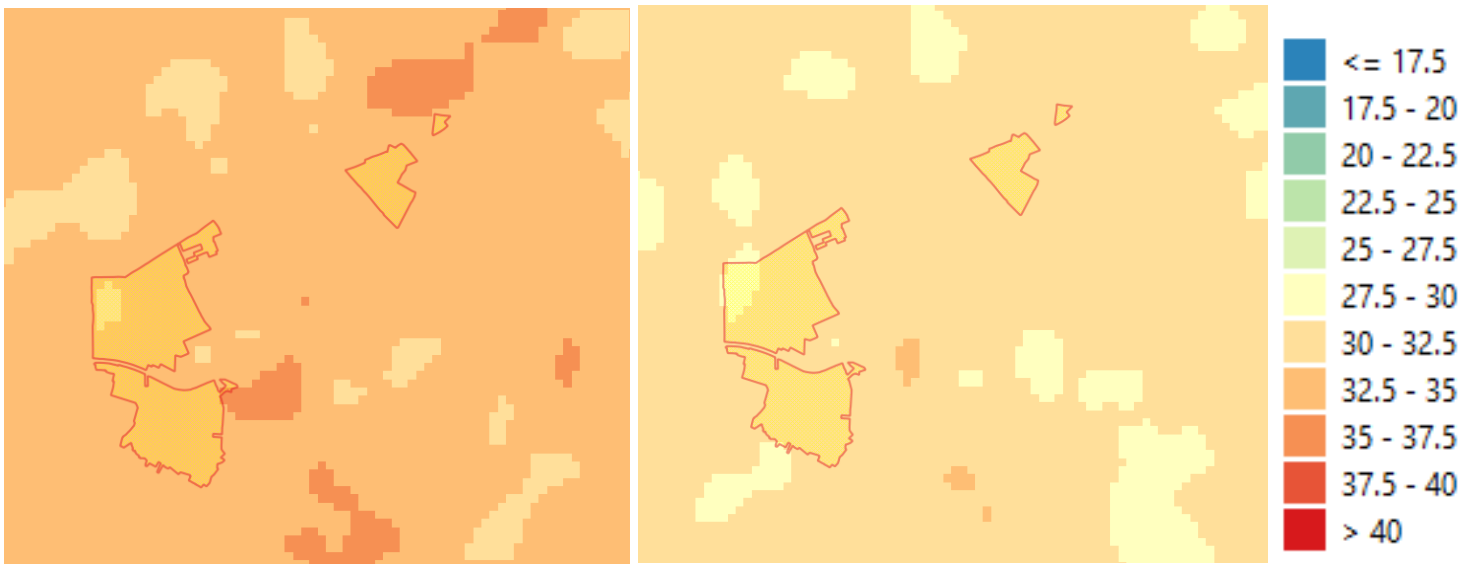

Por fim, destaca-se a participação da Lagoa da Pampulha como área onde foi recorrente o registro de temperaturas mais baixas, devido ao elevado calor específico deste fluido (da ordem de $1 \mathrm{cal} / \mathrm{g}^{\circ} \mathrm{C}$ ), que torna o processo de aquecimento mais lento do que estruturas solidificadas. Em contrapartida, cabe destaque à situação observada nas pistas dos aeroportos "Carlos Prates" e "Pampulha", que figuraram como núcleos de aquecimento mais frequentes no conjunto de observações do que áreas densamente edificadas, como as vilas e aglomerados. Neste caso, sugere-se que os baixos valores de albedo do asfalto negro atuaram como principais responsáveis pelo padrão de aquecimento diferencial da superfície.

Em resumo, as temperaturas médias de superfície das vilas e aglomerados se mostraram praticamente iguais às médias calculadas para toda a cidade de Belo Horizonte $\left(26,6^{\circ} \mathrm{C}\right.$ e $26,7^{\circ} \mathrm{C}$, respectivamente). Por outro lado, a média das mínimas e média das máximas calculadas para a extensão completa da capital mineira $\left(19^{\circ} \mathrm{C}\right.$ e $\left.36,6^{\circ} \mathrm{C}\right)$ foram mais contrastantes do que as obtidas nas vilas e aglomerados $\left(22,3^{\circ} \mathrm{C}\right.$ e $\left.30,7^{\circ} \mathrm{C}\right)$. Ambos os cenários são justificados pelos diferentes tipos de uso e cobertura da terra encontrados nestes recortes, sobretudo em função da disponibilidade de vegetação em fragmentos mais extensos quando se considera todo o município.

O gráfico 1 resume o comportamento quantitativo das variáveis ao longo do período de análise. Destaca-se a maior amplitude térmica de Belo Horizonte se comparada às vilas e aglomerados, bem como a similaridade entre as médias calculadas. O mapa 2, por sua vez, revela a evolução superficial das temperaturas de superfície no mesmo período. 
Gráfico 1: Evolução da temperatura de superfície média, mínima e máxima nas vilas e aglomerados de Belo Horizonte.

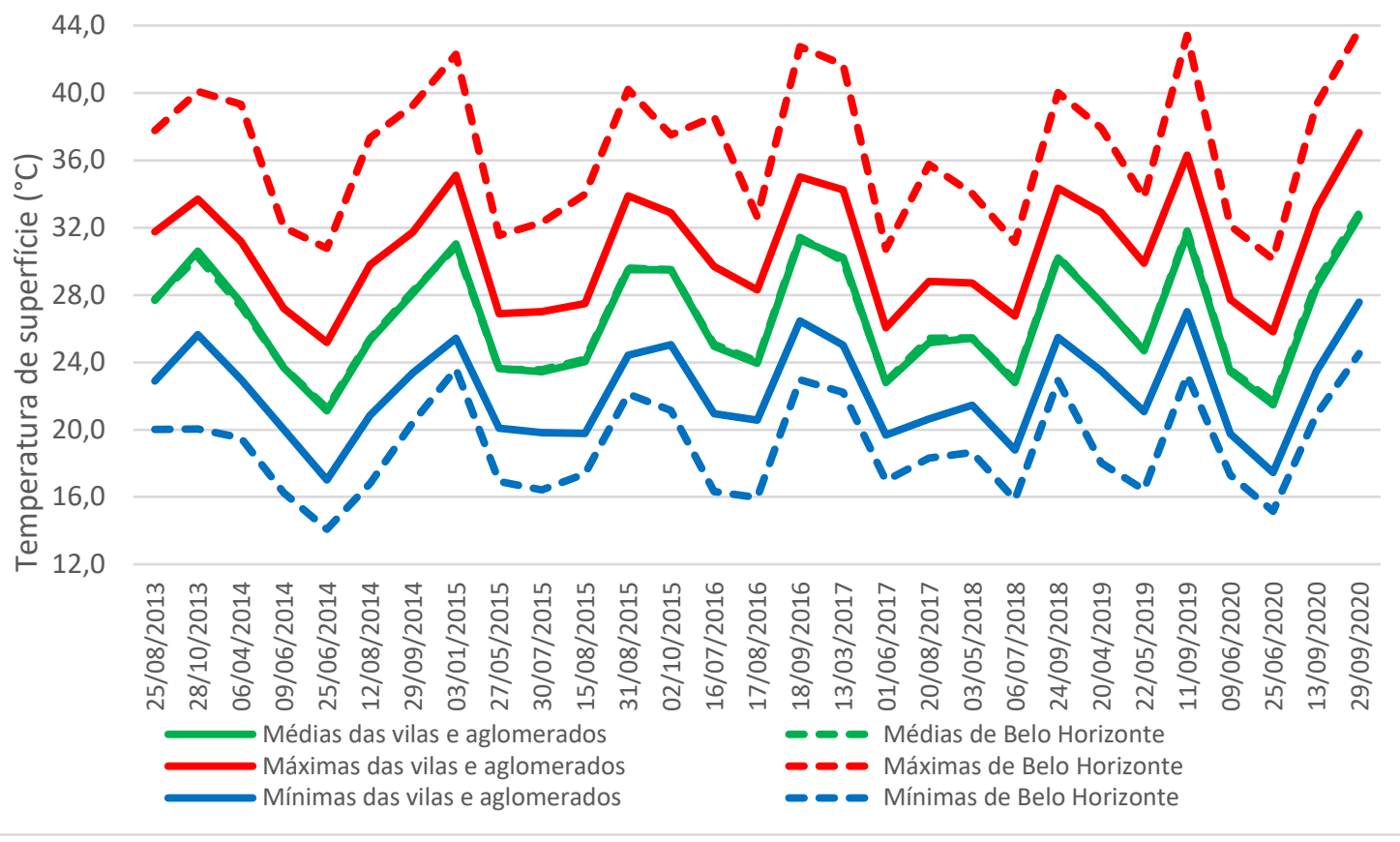

Mapa 2: Evolução da temperatura superficial em Belo Horizonte entre 2013 e 2020.

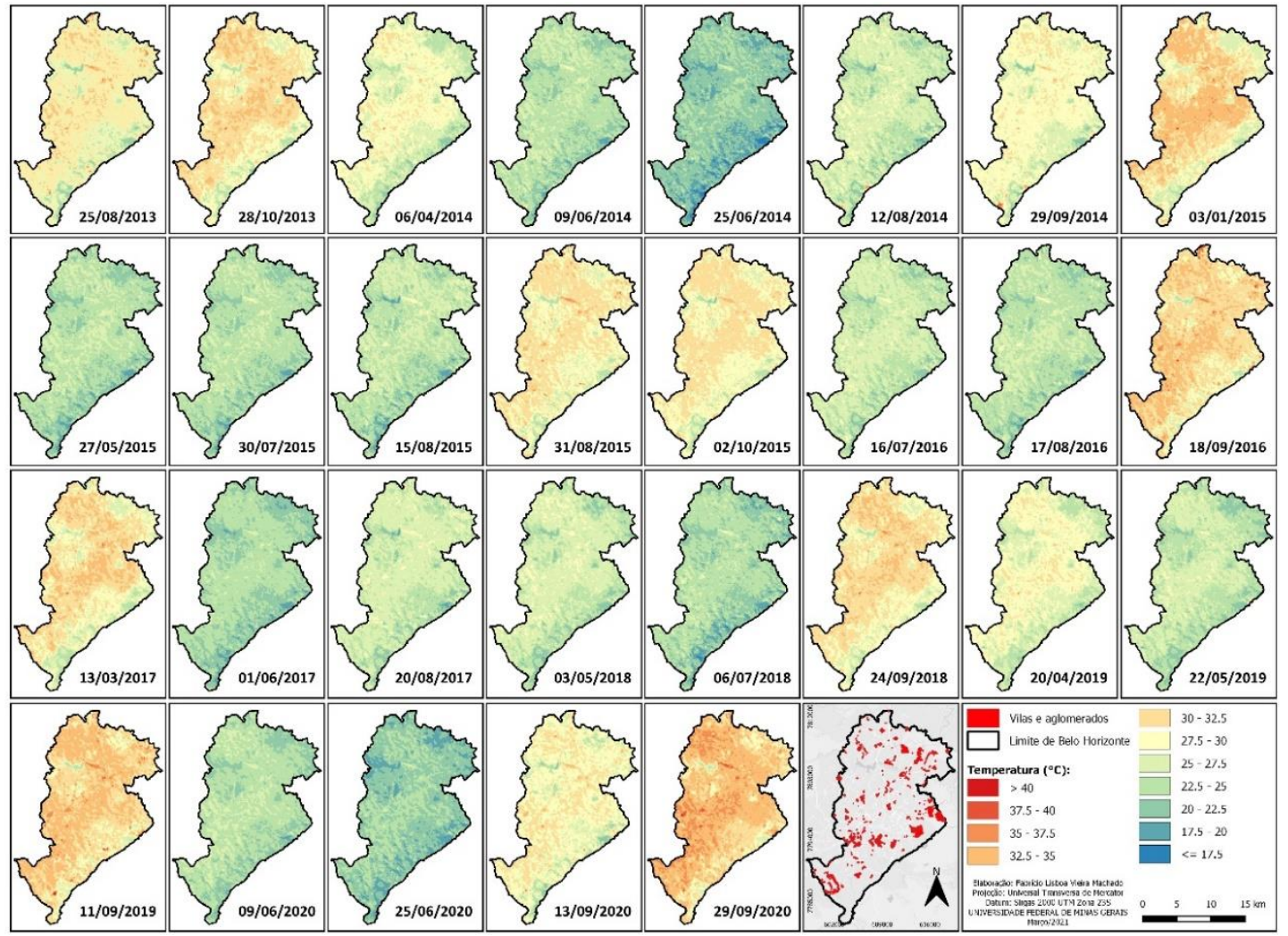


Em esforço de síntese, calculou-se a distribuição média da temperatura de superfície para Belo Horizonte no período de 2013 a 2020 (mapa 3), onde se mostrou evidente o direcionamento dos núcleos de calor superficiais pelos grandes galpões e estruturas com cobertura metálica.

Mapa 3: Distribuição da temperatura média de superfície estimada para Belo Horizonte entre 2013 e 2020.

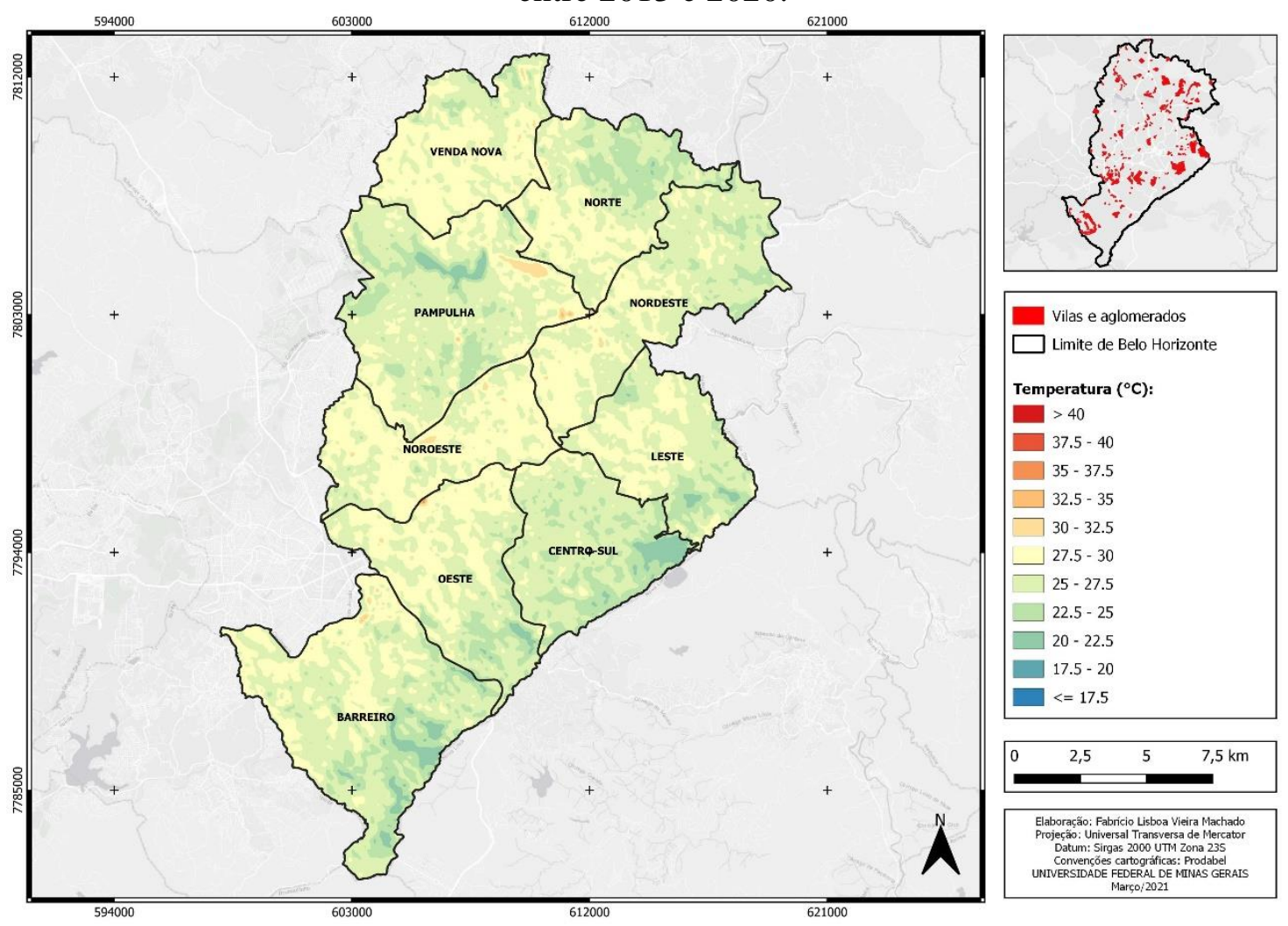

Além dos já citados anteriormente, ressalta-se o papel exercido pelos extensos telhados do Centro de Triagem de Cartas e Encomendas (CTCE) dos Correios, na regional Pampulha, e do conjunto de estruturas metálicas da empresa Mannesmann-Vallourec, na regional Barreiro. Também é curioso destacar o comportamento do estacionamento da Cidade Administrativa de Minas Gerais, que dada sua elevada extensão e consequente acúmulo de veículos, figurou como um dos núcleos de maior aquecimento superficial identificados na série temporal da pesquisa.

Por outro lado, condição interessante observada, não somente no mapa da distribuição média da temperatura de superfície, mas em todas as datas investigadas, foi a existência de zonas de baixo aquecimento no hipercentro de Belo Horizonte, muito provavelmente formadas pelo sombreamento perene da superfície gerado pelos arranha-céus da capital mineira no horário de passagem do satélite. 
Os maiores contrastes térmicos médios da superfície observados entre os núcleos de aquecimento e as áreas de entorno foram de aproximadamente $8,7^{\circ} \mathrm{C}$, registrado entre a Lagoa da Pampulha e a pista do aeroporto homônimo, e de $8,5^{\circ} \mathrm{C}$, entre a cobertura metálica do hipermercado Carrefour Pampulha e a área vegetada do campus da UFMG.

Diferentemente da hipótese inicialmente levantada, nenhuma vila ou aglomerado figurou como relevante núcleo de calor em Belo Horizonte do ponto de vista do aquecimento superficial, condição que não pode ser assumida para a temperatura do ar, diante das limitações dos métodos e técnicas empregadas neste artigo. O mapa 3 ilustra o resultado final calculado.

Por fim, no intuito de validar o modelo empregado, realizou-se o cálculo da regressão linear entre a temperatura da superfície (estimada) e a temperatura do ar (observada) na área onde se localiza a estação meteorológica do Inmet Pampulha. O coeficiente de determinação foi da ordem de 0,698, sugerindo aproximação razoável entre as medidas. A temperatura média da superfície no pixel correspondente à estação foi de $25,3^{\circ} \mathrm{C}$ para o período de análise da pesquisa, enquanto que a temperatura média do ar foi de $24,7^{\circ} \mathrm{C}$.

Os maiores desvios positivos observados pela análise dos resíduos da regressão (superfície mais quente que o ar) foram observados no dia 31/08/2015, sob atuação do Anticiclone Subtropical do Atlântico Sul, tipo de tempo estável e céu claro. Os maiores desvios negativos (superfície mais fria que o ar), por outro lado, foram observados em 09/06/2020, sob atuação do mesmo sistema sinótico, porém com presença de nebulosidade em dissipação em horários anteriores à passagem do satélite, o que pode justificar a condição observada, dado que a superfície tem capacidade de ganhar e perder calor de maneira mais veloz que o ar. A figura 5 ilustra a reta de regressão, enquanto que a figura 6 apresenta o cenário atmosférico citado. 
Figura 5: Regressão linear calculada entre a temperatura de superfície estimada por imagens do satélite Landsat-8 e a temperatura do ar observada na estação meteorológica do Inmet Pampulha (2013 a 2020).

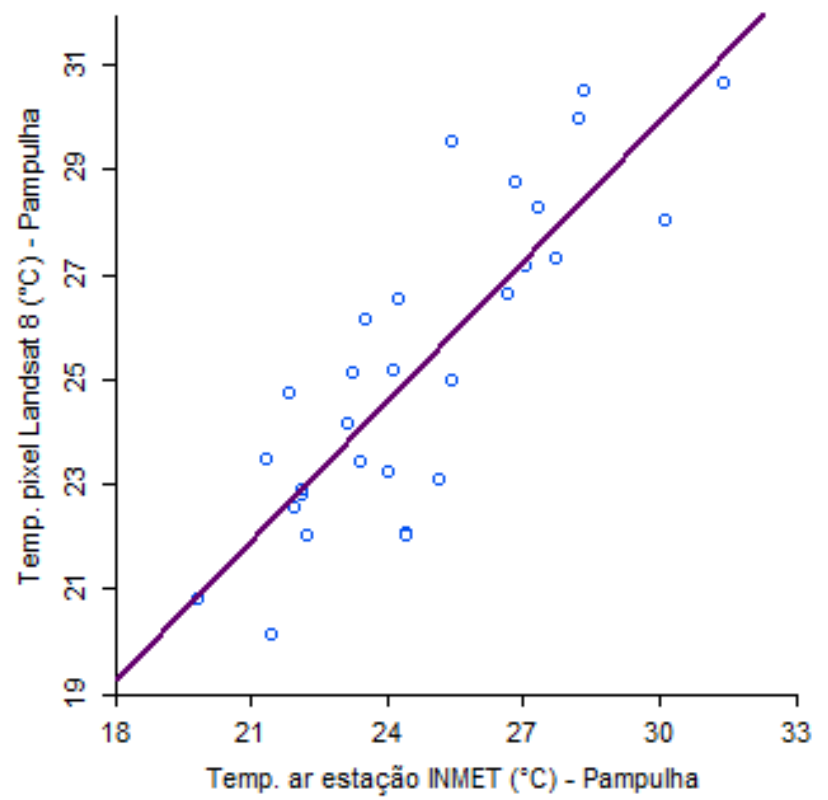

$\begin{array}{cccccccccc}\text { \#obs } & \mathrm{R}^{\wedge} 2 & \text { const a } & \text { std-err a } & \text { t-stat a } & \text { p-value a } & \text { slope b } & \text { std-err b } & \text { t-stat b } & \text { p-value b } \\ 29 & 0.698 & 3.229 & 2.805 & 1.152 & 0.260 & 0.892 & 0.113 & 7.905 & 0.000 \\ 0 & 0 & 0 & 0 & 0 & 0 & 0 & 0 & 0 & 0 \\ 29 & 0.698 & 3.229 & 2.805 & 1.152 & 0.260 & 0.892 & 0.113 & 7.905 & 0.000\end{array}$

Figura 6: Imagens dos satélites meteorológicos GOES13 e GOES16 para a América Latina em 31/08/2015 (esquerda) e 09/06/2020 (direita).
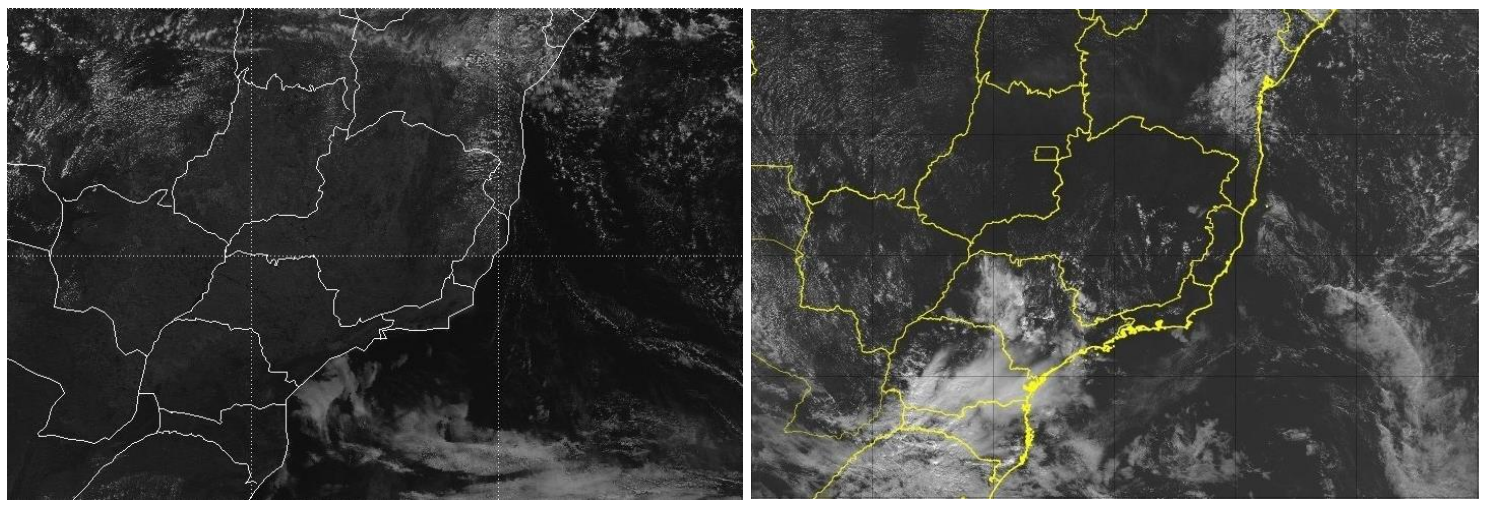

\section{4 - CONSIDERAÇÕES FINAIS}

A pesquisa se debruçou sobre a avaliação da temperatura de superfície das vilas e aglomerados de Belo Horizonte a partir de série temporal de imagens termais do satélite Landsat-8. Observou-se que, sobretudo para os picos de temperatura máxima, os resultados 
foram fortemente orientados por estruturas com revestimento metálico em superfície, tendo sido registrados valores superiores aos das principais vilas e aglomerados do município.

A vegetação também desempenhou importante papel na regulação de núcleos de calor urbanos, visto que mesmo nos maiores aglomerados mais densamente edificados, a presença de feições vegetacionais em fundos de vale foi responsável pela atenuação dos valores calculados.

Em comparação com as temperaturas médias calculadas para a extensão completa de Belo Horizonte, os valores obtidos para as vilas e aglomerados foram muito próximos. Os valores máximos e mínimos, por outro lado, experimentaram amplitude térmica muito maior quando considerada a mancha urbana total do município, resultado da diversidade de tipos de cobertura da terra.

Apesar de não identificar as vilas e aglomerados como núcleos de calor urbanos do ponto de vista do aquecimento superficial, a pesquisa não esgota o desenvolvimento de novos estudos para avaliação específica do comportamento da temperatura do ar nestes espaços e sua relação com impactos negativos na população residente.

Ainda, cabe refinamento nos métodos empregados nesta pesquisa, sobretudo no que se refere ao ajuste do modelo para cálculo da temperatura a partir da emissividade dos corpos de superfície.

Por fim, cabe destacar que ainda são escassos os trabalhos que se preocuparam em evitar análises da temperatura de superfície a partir de simples episódios ou situações pontuais, que retratam a relação dos sistemas atmosféricos e fatores de superfície naquele único instante. Nesta pesquisa, optou-se por investir em análise sucessiva, que contribuiu para a aproximação do sensoriamento remoto à abordagem geográfica do clima.

\section{REFERÊNCIAS BIBLIOGRÁFICAS}

ARTIS, D. A. \& CARNAHAN, W. H. Survey of emissivity variability in thermography of urban areas. Remote Sensing of Environment, Vol. 12(4), 1982.

ASSIS, W. L. O sistema clima urbano do município de Belo Horizonte na perspectiva têmporo-espacial. 2010. 299 p. Tese (Doutorado em Geografia) - Universidade Federal de Minas Gerais. Belo Horizonte, 2010.

AZEVEDO, T. R. O fluxo de calor gerado pelas atividades humanas. In: TARIFA, J. R. \& AZEVEDO, T. R. Os climas na cidade de São Paulo: teoria e prática. Revista GeoUSP. Volume 4. 2001.

BASTIAANSSEN, W.G.M. Estimation of land surface parameters by remote sensing under clear-sky conditions. PhD thesis, Wageningen University, Wageningen, The Netherlands, 1995. 
BARBOSA, H. P., DUBREUIL, V. \& AMORIM, M. C. C. T. Utilização de imagens do satélite Landsat 8 para a análise da emissividade e da temperatura de superfície da aglomeração urbana de Rennes (França). Anais do XVIII Simpósio Brasileiro de Sensoriamento Remoto. Santos, 2017.

BEZERRA, P. E. S., MORAES, E. T. I. \& SOARES, I. R. C. Análise da temperatura de superfície e do índice de vegetação no município de Belém na identificação das ilhas de calor. Revista Brasileira de Cartografia, 2018.

COELHO, A. L. N. \& CORREA, W. S. C. Temperatura de superfície celsius do sensor TIRS/Landsat 8: metodologia e aplicações. Revista Geográfica Acadêmica, v.7, n.1, p. 31-45, 2013.

EMPRESA DE INFORMÁTICA E INFORMAÇÃO DO MUNICÍPIO DE BELO HORIZONTE (PRODABEL). Infraestrutura de Dados Espaciais. Disponível em http://bhmap.pbh.gov.br/v2/mapa/idebhgeo. Acesso em 19 de dezembro de 2020.

FIALHO, E. S. Ilha de calor em cidade de pequeno porte: caso de Viçosa, na Zona da Mata Mineira. Tese (doutorado em Geografia). Departamento de Geografia. Faculdade de Filosofia, Letras e Ciências Humanas. Universidade de São Paulo, 2009.

GRONDONA, A. \& ROLIM, S. B. A. Separação de temperatura e emissividade a partir de imagens do infravermelho termal: análise de suas aplicações/restrições. Boletim de Ciências Geodésicas, Vol. 22, nº 1, pg. 16-34, Curitiba, 2016.

INSTITUTO BRASILEIRO DE GEOGRAFIA E ESTATÍSTICA. Resolução da Presidência. Define a data de término do período de transição definido na RPR 01/2005 e dá outras providências sobre a transformação entre os referenciais geodésicos adotados no Brasil. Rio de Janeiro, 24 de fevereiro de 2015.

INSTITUTO NACIONAL DE METEOROLOGIA. Mapa das Estações. Disponível em https://mapas.inmet.gov.br/. Acesso em 06/03/2021.

JIMÉNEZ-MUÑOZ, J.C. e SOBRINO, J.A. A generalized single-channel method for retrieving land surface temperature from remote sensing data. Journal of Geophysical Research, 2003, 108(D22). 4688.

JIMÉNEZ-MUÑOZ, J.C., CRISTÓBAL, J., SOBRINO, J.A., SÒRIA, G., NINYEROLA, M. e PONS, X. Revision of the Single-Channel Algorithm for Land Surface Temperature Retrieval From Landsat Thermal-Infrared Data. IEEE Transactions on Geoscience and Remote Sensing, 47(1), 2009, p. 339-349.

LIMA, D. Com $37,3^{\circ} \mathrm{C}$, BH tem setembro mais quente da história. Jornal Estado de Minas, Belo Horizonte, 28 de setembro de 2020. Disponível em: https://www.em.com.br/app/noticia/gerais/2020/09/28/interna_gerais,1189674/com37-3-c-bh-tem-setembro-mais-quente-da-historia-confira-recordes.shtml

LOMBARDO, M. A. Análise do fenômeno de lhas de Calor Urbanas, por meio da combinação de dados Landstat e Ikonos. In: XI Simpósio Brasileiro de Sensoriamento Remoto, Belo Horizonte, 2003. Anais. p.1741 - 1748, 2003.

MACIEL, S. A. \& OLIVEIRA, L. A. Avaliação dos valores gerados de temperatura de superfície dos sensores TIRs do satélite Landsat 8 aplicados ao perímetro urbano do município de Uberlândia - MG. Revista Ambiência Guarapuava. Vol.12. Ed. Especial pg. 821830, 2016. 
MACHADO, F. L. V. \& JARDIM, C. H. Indicadores climáticos de degradação ambiental em áreas urbanas: o Aglomerado da Serra em Belo Horizonte. 2014. In: SILVA, C. A.; FIALHO, E. S.; STEINKE, E. T. Experimentos em Climatologia Geográfica. Dourados: Ed. UFGD, 2014.

MONTEIRO, C. A. F. Teoria e clima urbano. São Paulo: IG06-USP. Série Teses e Monografias, n. $25,1976$.

Teoria e clima urbano: um projeto e seus caminhos, 2003. In: MONTEIRO, C. A. F.; MENDONÇA, F. Clima urbano. São Paulo: Ed. Contexto, 2003.

NOVO, E. M. L. M. Sensoriamento Remoto: princípios e aplicações. $4^{\mathrm{a}}$ ed., São Paulo, Editora Blucher, 2010.

PINTO, J. L. C.; SIlvA, F. S.; ElmirO, M. A. T., NÓBreGA, R. A. A. Análise comparativa dos mapeamentos de temperaturas obtidos por imagens termais e medidas de campo em Belo Horizonte - MG. Revista Geografias, Edição Especial, Belo Horizonte, 2017.

RIBEIRO, A. G. As escalas do clima. Boletim de Geografia Teorética, 23(45-46):288-294, Rio Claro, 1993.

SILVA, E. N. \& RIBEIRO, H. Alterações microclimáticas em ambientes de favela: Metodologia de avaliação empregada na favela de Paraisópolis - São Paulo. Revista GEOUSP - Espaço e Tempo. n.18, p. 171-186. São Paulo, 2005.

SILVA, E. N. \& RIBEIRO, H. Alterações da temperatura em ambientes externos de favela e desconforto térmico. Revista Saúde Pública, 40(4), pg. 663-670, 2006.

SOBRINO, J. A., RAISSOUNI, N., \& Li, Z. L. A comparative study of land surface emissivity retrieval from NOAA data. Remote Sensing of the Environment, 75(2), 256-266, 2001.

SOUSA, R. R. \& LIMA, S. C. Uso de imagem termal do satélite Landsat-8 para análise das variações de temperaturas do ar na cidade de Barra do Garças, estado de Mato Grosso. Revista Geografia, v.30, n.1, p.457-476, Londrina, 2021. 